\title{
Parque Industrial, de Patrícia Galvão: CARTografia feminista na SÃo Paulo EM MOdernizaçÃo
}

\author{
Industrial Park, by Patrícia Galvão: \\ FEMINIST CARTOGRAPHY IN SÃo PAUlo IN MODERNIZATION
}

Ludimila Moreira Menezes $^{1}$

DOI: 10.11606/issn.1981-7169.crioula.2017.134527

RESUMO: A contemporaneidade do romance em suas ressonâncias feministas permite pensar as personagens mulheres a partir de um processo múltiplo de interações e insurgências que se contrapõe à realidade chapada e uniforme de personagens resignadas com o devir de opressão ofertado pelo capitalismo. Com provocações que confrontam de imediato teleologias e racismos, o romance, margeado pela crítica comunista, vale-se de uma memória emocional para romper com o esquema pedagógico pleiteado pelo Partido Comunista e desferir suas histórias repletas do agora difícil, mas não impossível, de revoluções.

ABSTRACT: The contemporary aspect of the novel in its feminist ressonances allows the reader to think female characters through a multiple process of interactions and insurgencies that is placed against a flat and uniform reality of characters that are resighed with a future of oppression under capitalismo. With provocations that immediately confront teleology and racisms, the novel, bordered by the communist critique uses na emotional memory to rupture the pedagogical scheme defended by the communist party and offers its stories filled with a present of difficult but not impossible revolutions.

1 Doutora pelo Departamento de Literatura e Teorias Literárias da UnB 
PALAVRAS-CHAVE: Literatura brasileira; Modernidade; Feminismo; Antropofagia.

KEYWORDS: Brazilian literature; Modernity; Feminism; Antropophagy.

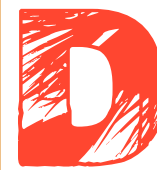

iante do romance Parque industrial, de Patrícia Galvão, pretendo aqui apresentar e discutir as relações entre organização textual e contexto, tendo em vista as perspectivas e visadas do romance que problematizam e tensionam regimes normativos de representação da cidade de São Paulo e das mulheres operárias. Sob esse aspecto, pretendo examinar e discutir a maneira como a amizade, a militância e seus efeitos de partilha forjam enunciados, saberes sobre e desde as noções de enfrentamentos e resistências.

Nesse sentido, elejo aqui alguns fatos para tornar inteligível a relação de Parque industrial, escrito em 1933, com a adesão de Patrícia Galvão ao Partido Comunista ${ }^{2}$ em 1931. Convidada para um recital de poesia em Buenos Aires como embaixadora da Antropofagia, Pagu recebe material de propaganda do Partido Comunista. Já no Brasil, em 1931, com um grupo de amigos, entre eles, Oswaldo Costa e Astrogildo Pereira, esbo-

2 Sobre a filiação de Patrícia Galvão, ver o estudo de Augusto de Campos, Pagu: vida e obra, que conta com textos, crônicas, trechos de livros da própria escritora e, ainda, com artigos e testemunhos de Antonio Risério, Kenneth David Jackson, Geraldo Ferraz. Entre esses artigos, destaco a análise de Antonio Risério, que, ao tratar da conjuntura política do Brasil no início da década de trinta, retrata os meandros ideológicos de alguns intelectuais, como Pagu: "A revolução de 30 sacudia o país, e a crise mundial do capitalismo, deflagrada pela depressão de 29, acabaria repercutindo na estrutura econômica da sociedade brasileira, modificando-a. Vivia-se, então, uma daquelas conjunturas em que, conforme a expressão de Celso Lafer, as discussões sobre o papel da política na sociedade ganham 'intensidade prática'. Escritores e intelectuais, naturalmente, não flutuam acima de tais problemas. E os modernistas 'históricos' se fragmentaram em rumos variados. Pagu e Oswald, juntos, evoluíram rapidamente para posições de esquerda, 'guinada' ideológica que ambos tratariam literalmente" (RISÉRIO, 2014 pp. 18-19). 
ça o projeto do jornal O Homem do Povo. Em 1932 o Partido exige que Patrícia Galvão vá para o Rio de Janeiro, cumprindo as determinações do projeto proletário; a escritora, diante das diretrizes do Partido e de seu comprometimento ideológico, trabalha como costureira, empregada doméstica, lanterninha, metalúrgica. Sobre seu retorno a São Paulo, depois da Revolução Constitucionalista, Furlani e Ferraz observam:

Com a depuração feita pelo Partido contra os intelectuais, ela é afastada por tempo indeterminado da ação partidária e, para provar sua sinceridade de propósitos, começa a escrever o romance Parque industrial (FURLANI; FERRAZ, 2010, p. 113).

Publicado em janeiro de 1933, Parque industrial surgia concomitante à necessidade de Galvão de demonstrar sua convicção comunista ao Partido e continuar filiada ao organismo. A apropriação, com projeção de características, de nomes como Rosa Luxemburgo e Herculano Souza por seus personagens produz efeitos políticos que acenam às diretrizes do Partido Comunista. A autora recorre à estratégia do pseudônimo e lança o romance sob a alcunha de Mara Lobo. O engajamento político que ecoa nos registros de opressão, articulação e resistência ao longo do enredo reverte o escopo do Partido, que era meramente o da propaganda; assim, o romance desdobra temas que vão além do binarismo das classes sociais, das contendas entre patrões e operários.

No largo das assimetrias sociais, das tensões cotidianas, o romance de Patrícia Galvão potencializa as possibilidades do dizer das mulheres pobres, investe nas performances das 
sociabilidades marginais, produz sentidos de deslocamentos, de resistências. A identificação, promovida pela narradora, entre mulheres e mercado de trabalho produz, por um lado, críticas ao aniquilamento físico e subjetivo operado pelo regime fabril e, por outro, revela um espaço de articulação entre as mulheres nesse espaço, a priori, de controle masculino.

As representações de progresso material que circulavam no projeto do Estado nacional varguista são problematizadas e subvertidas na linguagem ficcional de Patrícia Galvão, a ironia da narradora como categoria revolucionária que revela as mazelas, as disparidades e desmascara o tom apaziguador desse processo que reivindica e produz trabalhadores disciplinados como a construção de personagens que em suas experiências periféricas tensionam as categorias de progresso, de desenvolvimento e de modernização.

Parque industrial explora traçados urbanos revelados pela atração entre modernização e precarização de vidas; assim, cabe evidenciar os vínculos entre a elite paulistana, com seu tradicional ideal de brasilidade, e o projeto de modernização empreendido pelo governo Vargas, para discutir como a produção de Patrícia Galvão se inscreve em um outro campo de saber, de resistência e interferência nas matrizes modernistas e também varguistas de cultura, de literatura.

Acerca do ethos que acossa e forja a realidade de Patrícia Galvão e das personagens do romance, os historiadores Adriana Lopez e Carlos Guilherme Mota (2008, p. 640) avaliam que, com a chegada de Vargas ao poder, instaurou-se um novo sistema de forças que combinou ideias de reforma de uma burguesia liberal-conservadora, porém modernizadora, 
com práticas neocoronelísticas e burocráticas na máquina do Estado, mobilizador das aspirações populares do mundo do trabalhismo. Os autores (2008, p. 677) reportam-se ao poema "O medo", de Carlos Drummond de Andrade, para ilustrar o clima de tensão que funda a construção do Estado Novo varguista, torturas e assassinatos que marcaram as ações do Tribunal de Segurança Nacional: "Chovia, ventava, fazia frio em São Paulo". Nesse compêndio de História do Brasil, os autores fazem menção a Pagu como "a bela e romântica revolucionária" (LOPEZ; MOTA, 2008, p. 677) e novamente se valem da intertextualidade, agora com Darcy Ribeiro, para retratar Patrícia Galvão:

Segundo Darcy Ribeiro, foi violentada com buchas de mostarda e martirizada com arame incandescente na uretra. No ódio àquela criatura bela e inteligente, condensavam-se quatrocentos anos de sadismo escravista, com suas cultivadas técnicas de tortura, embaladas pelo horror patriarcal à dissidência, à inteligência e à autonomia feminina. Pagu sobreviveu (LOPEZ; MOTA, 2008, p. 677).

É no contraste com os efeitos eufóricos da modernização, como a segregação espacial, que Parque industrial remonta a história de sujeitos possíveis que se articulam entre suas (in) visibilidades, expectativas, estereótipos e experiências desvinculando-se de um projeto narrativo de matriz androcêntrica. O que ressalto dessa configuração narrativa inovadora é a correlação entre amizade e resistência. Se, em Um teto todo 
seu (1928), Virginia Woolf de um lado encara a questão do silenciamento na representação de mulheres personagens nas narrativas e na apresentação de mulheres escritoras, de outro disponibiliza a tese de que a autonomia artística e criativa das mulheres relaciona-se diretamente com o acesso ao mundo do trabalho e ao direito de um lugar próprio para produzir seus escritos, sintetizados na imagem de um quarto e de uma quantia de libras esterlinas. No ensaio feminista é emblemática a sequência que aborda a obra da fictícia Mary Carmichael. Além de romper com pressupostos de um certo estilo autoral destinado às mulheres, Woolf acena para um tema considerado tabu e que será retomado por Patrícia Galvão em seu romance de 1933:

[...] o amor, a amizade entre as mulheres. Então, a relação entre as amigas Chloe e Olívia, que compartilhavam um laboratório, permite que a escritora especule o seguinte: Suponhamos, por exemplo, que os homens só fossem representados na literatura como apaixonados pelas mulheres, e nunca fossem amigos de homens soldados, pensadores, sonhadores; que pequena quantidade de papeis nas peças de Shakespeare Ihes poderiam ser atribuídos, como sofreria a literatura (WOOLF, 1985, p. 110).

Mediante as problematizações de Virginia Woolf, encontro Parque industrial, com uma distância de cinco anos, recobrando essa interação, essa amizade entre mulheres. Com efeito, os estudos de Francisco Ortega sobre a dinâmica da modernidade permitirão uma melhor compreensão das amiza- 
des constituídas no romance, suas discussões sobre o caráter familial das instituições modernas indicam como a sociedade deixa de experimentar, inventar outras formas de vida. Parque industrial parece acenar à assertiva de Ortega: "A amizade é um fenômeno público, precisa do mundo e da visibilidade dos assuntos para florescer" (ORTEGA, 2002, p. 161). As personagens de Parque industrial ocupam as fábricas em reuniões na calada da noite pulverizando nossas formas de sociabilidade que conjugam transformação do político, de si e dos outros. Diante da norma de despolitização, amizade e militância penetram os espaços públicos com as barricadas da solidariedade. Sobre a amizade como exercício do político, Francisco Ortega afirma: "A amizade constitui uma nova sensibilidade e uma forma de perceber diferente, baseada no cuidado e na encenação da 'boa distância'” (ORTEGA, 2000, p. 117).

É perceptível em Parque industrial que as vozes das personagens operárias fraturam o pressuposto de que o sujeito/ personagem universal masculino é o único habilitado a trabalhar nas fábricas, participar de assembleias, fazer greves, executar ações antes integradas ao repertório das masculinidades. Sobre a visão e construção masculina acerca da identidade de mulheres trabalhadoras, oscilando entre o papel de figuras passivas e frágeis, Margareth Rago (2008, p. 579), em seu estudo sobre trabalho feminino e sexualidade, evidencia a necessidade de a historiografia debruçar-se sobre a percepção que essas mulheres tinham de suas condições social, sexual e individual. Nesse sentido, a autora avalia a narrativa de Pagu como pioneira nesse percurso: 
Pagu, Patrícia Galvão, ou ainda Mara Lobo, escritora feminista e comunista dos anos 30, foi uma das poucas mulheres a descrever, no romance Parque industrial, a difícil vida das operárias de seu tempo: as longas jornadas de trabalho, os baixos salários, os maus-tratos de patrões e, sobretudo, o contínuo assédio sexual (RAGO, 2008, p. 578).

Também sobre esse imaginário de participação feminina no mundo do trabalho entre os anos de 1914 e 1940, encontra-se o trabalho de Susan K. Besse (1999). No que concerne ao governo Vargas, a autora discute o projeto ideológico que exigia a conciliação entre a demanda de mão de obra feminina pelos empregadores, a demanda de igualdade pelas mulheres e a necessidade social mais ampla de utilizar as mulheres e a família de maneira mais segura para as tarefas de reprodução social. Assim, o programa de modernização e centralização política, bem como seu escopo de fragmentar o poder da oligarquia rural e, ao mesmo tempo, estabelecer o controle sobre as massas urbanas em ascensão, privilegiando sempre o ideal de família como estratégia de manutenção da hierarquia social, institui um sistema de hierarquia de gêneros que moderniza a desigualdade. Parque industrial percorre esse período de transição, no qual a responsabilidade pelo controle e sujeição da classe operária urbana passa das fábricas para o Estado; no qual, ainda, o voto feminino, aprovado pelo Congresso em 1932, é destinado somente às mulheres alfabetizadas. Sobre esse momento, Susan Besse argumenta que 
Os empregadores as recrutavam avidamente para o setor de serviços da economia urbano-industrial em expansão, mas o código civil de 1916 definia seu marido como cabeça do casal perante a lei, investido do poder de autorizar ou proibir que ela seguisse uma carreira profissional. Além disso, como ela era encaminhada para trabalhos "femininos" rotineiros e muito mal pagos, seu emprego antes suplementava a renda familiar e promovia o desenvolvimento nacional do que Ihe permitia alcançar a autonomia individual e auto-realização (BESSE, 1999, p. 11).

Em Parque industrial, é no espaço fabril que acontece a emergência de resistências, derruindo a ideia de que os trabaIhadores sejam passivos, manobrados pela estrutura do governo Vargas, que captura a classe trabalhadora através dos sindicatos. Na representação da urbe paulistana delineada no romance, os imigrantes não são os únicos agentes de manifestações da classe trabalhadora contra a exploração e desqualificação empreendidas pelo discurso policial e médico da elite paulistana, também na dinâmica do movimento operário estão presentes as performances políticas de trabalhadoras negras e brancas e de brancos pobres. Além da lituana Rosinha, Otávia e Matilde são duas outras lideranças na narrativa, e são brasileiras.

A escolha de Patrícia Galvão de apresentar essas muIheres brasileiras pobres e trabalhadoras contraria as expectativas do Partido, que não reivindicara a problematização de gênero no romance proletário; como também as diretrizes da gestão cultural centralizadora e intervencionista do governo 
getulista, que almejava a constituição de uma nacionalidade assentada no equilíbrio das múltiplas etnias, raças e classes, longe da ameaça política chamada comunismo.

Embora o romance proletário inscreva-se no imaginário combativo defendido pelo Partido, as trajetórias das personagens apresentam outros cursos, outros comprometimentos, como a crítica à opressão feminina e à prostituição, que não são alvos programáticos da agenda partidária. Nesse sentido, evidencia-se no romance um processo de tomada de consciência de gênero. A voz narrativa, por exemplo, forja um inquietante discurso sobre a condição das personagens operárias, escapando das diretrizes do Partido, que preconizam uma transformação nas relações de classe, não nas de gênero. A relação entre a dupla jornada de trabalho e a maternidade das trabalhadoras, bem como a questão do trabalho infantil, repercute nas inquietações da narradora:

Novamente as ruas se tingem de cores proletárias. É a saída da Fábrica. Algumas têm namorados. Outras, não. Procuram. Mães saem apressadas para encontrar em casa os filhos maltratados, que nenhum gatuno quer roubar. A limosine do gerente chispa espaIhando o pessoal. Uma menina suja alisa o paralama com a mão chupada (GALVÃO, 2006, p. 22).

A rotina autômata, a concepção normativa de interação entre os funcionários e o adestramento do corpo para o meIhor aproveitamento do tempo são registros submetidos a uma crítica materialista pelo projeto ficcional. Dessa forma, 
as personagens denunciam e tentam apresentar triagens de resistências políticas para os dramas do Brás e para alhures, onde a matriz capitalista de regulamentação de corpos exerce a produção dos estereótipos femininos exaustivamente reproduzidos, da violência para inscrever suas práticas de atuação e seus domínios. A dicotômica relação entre grupos e suas expectativas - o engajamento proletário de um lado e a premência de ascensão ao território elitista de outro - atinge seu paroxismo com as personagens Eleonora e Otávia. Enquanto uma encara o casamento como único meio capaz de arrancá-la do Brás, a outra rechaça a conjugalidade com um burguês convertido à luta comunista pela simples possibilidade de suas ideias ameaçarem o projeto de seu grupo político. Sob esse contexto, a história de Eleonora, estudante do curso normal que vislumbra, na conjugalidade com o rico Alfredo, a possibilidade de se mudar do bairro pobre para o Hotel Esplanada, problematiza a idealização do casamento e a consequente inscrição simbólica em um mundo feminino legítimo, seguro.

Tendo em vista esse recorte, e atentando à relevância do corpo e da alma como sustentáculos das forças de poder e de saber (FOUCAULT, 2009a), observo a trajetória de Corina a partir da atuação poliforma das tecnologias do poder sobre o seu corpo. A articulação entre as sujeições da personagem à sua mãe, ao padrasto Florino, às promessas irrealizáveis do amante burguês Arnaldo, à gravidez não reconhecida e ao universo de violência anunciado pela prostituição revela um embate de dominações em que o corpo da personagem experimenta efeitos dessas relações generizadas: 
Corina remenda, esforçando a vista. Por que nascera mulata? É tão bonita. Quando se pinta então! O diabo é a cor! Porque essa diferença das outras! O filho era dele também. E se saísse assim, com a sua cor de rosa seca! Por que os pretos têm filhos? (GALVÃO, 2006, p. 49).

O questionamento a essa reiteração do feminino dicotômico (santa $x$ prostituta) aparece concomitante à apresentação da trajetória da personagem Corina. Assim, os meios encontrados para Corina escapar do esperado papel social de vítima são as relações amistosas com suas colegas do ateliê. Destacando o papel do contato, da presença do outro, Parque industrial encara a subjetividade como uma construção coletiva, nos termos de Francisco Ortega. Dessa forma, a aposta nessa interação possibilita a construção de novos arranjos de sociabilidade envolvidos por componentes libertários:

Diante de uma sociedade que nos impõe a tarefa de saber quem somos, de descobrir a verdade sobre nós mesmos e que monopoliza as formas de sentir e de se relacionar, o cultivo de outras formas de relação pode levar a substituir a descoberta de si pela invenção de si, pela criação de múltiplas formas de existência (ORTEGA, 2000, p. 114).

As representações das personagens não são arrematadas de imediato pela escritora, elas se deparam com barreiras que sugerem modulações, tensões nesse processo. As sujeições à normalidade delineadas pelo sistema capitalista são 
enfrentadas por dois baluartes no transcorrer da narrativa: o engajamento comunista e a amizade. As performances existenciais de Matilde ilustram essa análise, inicialmente apresentada como menina fútil, constrangida pela sua pobreza, deslocada do eixo revolucionário encarnado por Rosinha e Otávia, a construção da narrativa abre espaço para o desmonte, a transfiguração de Matilde a partir da amizade com as operárias da fábrica.

Compreender esse espaço da amizade em Parque industrial é fundamental para apreender as negociações geralmente efetivadas em encontros político-afetivos em que revolução proletária e amizade expressam juntas a possibilidade de se desenvolverem novos marcos e direitos relacionais. Sobre esse aspecto, o projeto foucaultiano de uma ética da amizade no contexto de uma possível atualização da estética da existência destaca que é possível transcender o marco da autoelaboração individual para que se experimente uma vivência em uma dimensão coletiva. A amizade supera a tensão entre o indivíduo e a sociedade mediante a criação de um espaço intersticial (uma subjetivação coletiva) suscetível de considerar tanto necessidades individuais quanto objetivos coletivos e de sublinhar sua interação. Nem todas as subjetivações têm um tipo de sujeito como objetivo; existem subjetivações sem sujeito (de tipo acontecimento) e subjetivações coletivas, às quais a amizade pertence.

Para tentar compreender a função da militância na narrativa, é preciso evidenciar a problemática da ansiedade no romance, que está, a meu ver, tanto na escolha da representação de mulheres operárias, quanto na crítica à produção de 
sociabilidade engendrada pelo capitalismo. Considero, pois, as reflexões de Harold Rosenberg no tocante às artes plásticas para retomar a questão da ansiedade na produção desse romance. Conforme esboçado pelo autor (ROSEMBERG, 2004 , p. 19), a ansiedade aparece na forma de uma vontade de que a arte continue existindo a despeito das condições que possam tornar sua existência impossível; daí, a importância de encará-la a partir da reflexão que os artistas fazem acerca do seu papel em relação às outras atividades humanas. Sobre esse aspecto, a noção de que a ansiedade gera o compromisso da ação seria identificada na narrativa pelo apelo à militância política, artifício da narradora que se alia com outro (de matiz distinto e que reforça o combate às formas de opressão institucionalizadas): as relações de amizade exploradas nesse parque industrial que é São Paulo.

A partir do monopólio da violência, o Estado institui a segurança e a legitimidade do regime capitalista em suas práticas autoritárias; no romance, a morte de Alexandre, pai de Carlos Marx e de Frederico Engels e amigo de Otávia, no comício do Largo da Concórdia (no Brás), é o derradeiro acontecimento-confronto entre polícia e trabalhadores. A discussão entre policiais e manifestantes constrói e oferece um espaço de sensibilidade que desvenda outros olhares àquela manifestação. Desligados do traço corporativo que une alguns policiais, inclusive um que leva no braço um distintivo de luto, eles se despem do discurso institucional: "Não temos nem opinião nem vontade. São ordens! - Se eu mandasse, era o tenente que eu pisava! - Minha mulher é operária..." (GALVÃO, 2006, p. 113). 
O dístico coerção capitalista e consentimento operário é desconstruído na medida em que oposições políticas se disseminam na narrativa. Os burburinhos e as pautas das reuniões atualizam a discussão de temas como maternidade e moradia a partir dos anseios das operárias:

Uma operariazinha envelhecida grita: - Minha mãe está morrendo! Ganho 50 mil-réis por mês. O senhorio me tirou tudo na saída da oficina. Não tenho dinheiro para remédio. Nem para comer (GALVÃO, 2006, p. 33).

Patrícia Galvão também analisa o imbricado entrelaçamento entre ética burguesa e o papel dos trabalhadores no processo de transformação do mundo capitalista. É através das cenas que envolvem Eleonora, ex-estudante da Escola Normal do Brás, e Alfredo, um rico intelectual marxista, habitante do Hotel Esplanada, que a narradora evidencia na moralidade burguesa, nos conflitos ideológicos, movimentos de cooptação e de militância. Não obstante o tom pedagógico, apologético da proletarização do burguês Alfredo, é perceptível no romance o alerta ou uma espécie de denúncia de que o Partido só aceita sujeitos de concordâncias. $O$ fato de Alfredo Rocha se alinhar ao trotskismo compromete sua permanência no Partido e seu envolvimento com a engajada Otávia. Antes de tomar a expulsão de Alfredo a partir de seu viés e dimensão didática, reporto-me à história da escritura de Parque industrial. Não seria a construção do personagem 
Alfredo uma condensação dos registros de arbitrariedades do Partido experimentadas pela própria escritora, ou, como interpreta o brasilianista Kenneth David Jackson, o avatar de Oswald de Andrade, o burguês oscilante?

A dimensão trágica do último capítulo de Parque industrial, chamado RESERVA INDUSTRIAL, não encobre a tópica da filiação política, um dos eixos estruturadores da narrativa, mas faz emergir rastros de sentido que, se não revelam algo da impotência da fé comunista, exploram a desilusão e a angústia advindas de uma sociedade em fundação e constante atração pelos domínios patriarcais e capitalistas. Esse mundo acossado pela catástrofe estaria mais do que entrevisto, personificado nos meandros da personagem Corina:

Nunca mais trabalhara. Quando tem fome abre as pernas para os machos. Saíra da cadeia. Quisera fazer vida nova. Procurara um emprego de criada no Diário Popular. Está pronta a fazer qualquer serviço por qualquer preço. Fora sempre repelida. Entregara-se de novo (GALVÃO, 2006, p. 118).

Nas impressões daquela cidade agitada, surgem representações em que o aspecto movimentado, cheio de vigor e de batalhas se esvai gradativamente, e a cor cinza de São Paulo intumesce ainda mais o centro urbano só agora da fome e frio dos pobres. A imagística de São Paulo em Parque industrial forja uma iconografia ambivalente que entrecruza opressão, resistência, afetos, ressaltando a corporeidade e as tramas subjetivas de uma cidade moderna. Para se chegar de fato a 
Parque industrial, é preciso atravessar uma espessa camada de fumaça historiográfica que o separa dos leitores. Não falo da tessitura fisiológica de São Paulo e suas mazelas advindas da industrialização, falo dos rótulos de panfleto político, que o coloca nas prateleiras positivistas dos romances representantes de escolas e tendências, deixando escapar suas contemporâneas problematizações político-subjetivas.

\section{RefERÊnCIAS BibLIOGRÁfICAS:}

BESSE, Susan K. Modernizando a desigualdade: reestruturação da ideologia de gênero no Brasil de 1914-1940. Tradução: Lólio Oliveira. São Paulo, Edusp, 1999.

FOUCAULT, Michel. Vigiar e punir: o nascimento da prisão. Tradução: Raquel Ramalhete. $36^{a}$ edição. Petrópolis: Vozes, 2009.

FURLANI, Lucia Maria Teixeira; FERRAZ, Geraldo. Fotobiografia de Patrícia Galvão. Santos: Unisanta; São Paulo: Imprensa Oficial do Estado de São Paulo, 2010.

GALVÃO, Patrícia. Parque Industrial. Rio de Janeiro: José Olympio, 2006.

LOPEZ; MOTA. História do Brasil: uma interpretação. São Paulo: SENAC, 2008. 
ORTEGA, Francisco. Para uma política da amizade: Arendt, Derrida, Foucault. Rio de Janeiro: Relume Dumará, 2000. . Genealogias da amizade. São Paulo: lluminuras, 2002.

RAGO, Margareth. "Trabalho Feminino e Sexualidade". In: DEL PRIORE Mary (Org.); BASSANEZI, Carla (coord.) História das Mulheres no Brasil. São Paulo: Contexto, 2008. RISÉRIO, Antônio. Pagu: vida-obra, obravida, vida. In: CAMPOS, Augusto de. Pagu: vida e obra. São Paulo: Companhia das Letras.

ROSENBERG, Harold. Objeto ansioso. Tradução de Vera Pereira. São Paulo: Cosac \& Naify, 2014.

WOOLF, Virginia. Um teto todo seu. Tradução: Vera Ribeiro. Rio de Janeiro: Nova Fronteira, 1985.

Submissão: $17 / 07 / 2017$

Aceite: 28/09/2017 